\title{
Positron Emission Tomography and Fluorodeoxyglucose Studies of Metabolic Hyperfrontality and Psychopathology in the Psilocybin Model of Psychosis
}

\author{
F. X. Vollenweider, M.D., K. L. Leenders, M.D., C. Scharfetter, M.D., P. Maguire, Ph.D., \\ O. Stadelmann, Ph.D., and J. Angst, M.D.
}

The effects of the indolehallucinogen psilocybin, a mixed 5-HT 2 and 5-HT, agonist, on regional cerebral glucose metabolism were investigated in 10 healthy volunteers with PET and [F-18]-fluorodeoxyglucose (FDG) prior to and following a 15- or 20-mg dose of psilocybin.

Psychotomimetic doses of psilocybin were found to produce a global increase in cerebral metabolic rate of glucose (CMRglu) with significant and most marked increases in the frontomedial and frontolateral cortex $(24.3 \%)$, anterior cingulate $(24.9 \%)$, and temporomedial cortex $(25.3 \%)$. Somewhat smaller increases of CMRglu were found in the basal ganglia (18.5\%), and the smallest increases were found in the sensorimotor (14.7\%) and occipital cortex $(14.4 \%)$. The increases of CMRglu in the prefrontal cortex, anterior cingulate, temporomedial cortex, and putamen correlated positively with psychotic symptom formation, in particular with hallucinatory ego disintegration. The present data suggest that excessive $5-\mathrm{HT}_{2}$ receptor activation results in a hyperfrontal metabolic pattern that parallels comparable metabolic findings associated with acute psychotic episodes in schizophrenics and contrasts with the hypofrontality in chronic schizophrenic patients. [Neuropsychopharmacology, 16:357-372, 1997] (C) 1997 American College of Neuropsychopharmacology
KEY WORDS: Psilocybin; Model psychosis; 5-HT, receptor; Psychopathology; Human; PET; [F-18]-Fluorodeoxyglucose (FDG); Schizophrenia

Psilocybin (o-Phosphoryl-4-hydroxy-N,N-dimethyltryptamine) and LSD (d-lysergic acid diethylamide) are two potent indolehallucinogens that can induce a psychosislike syndrome in humans that resembles in various aspects the first manifestation of schizophrenia (Hofmann 1968; Leuner 1981). Ego disorders and perceptive changes of surroundings are especially prominent features of psy-

From the Research Department, (FXV, CS, JA) Psychiatric University Hospital of Zürich, Zürich, Switzerland; and the PET Department (KLL, PM, OS), Paul Scherrer Institute, Villigen, Switzerland.

Address correspondence to: Dr. F.X. Vollenweider, Psychiatric University Hospital, P. O. Box 68, CH-8029 Zürich, Switzerland.

Received December 20, 1995; revised October 14, 1996; accepted October 17, 1996 chedelic and endogenous psychotic states (Fischman 1983). Because of the structural similarities between psilocybin, LSD, and serotonin (5-hydroxytryptamine, 5-HT), early investigators hypothesized that the serotonergic system might play a critical role in the pathophysiology of schizophrenia (Gaddum and Hammeed 1954; Wooley and Shaw 1954). More recently, this hypothesis achieved renewed support, first by a growing body of electrophysiological, behavioral and radioligand-binding studies suggesting that LSD and psilocybin exert their psychological effects through excessive $5-\mathrm{HT}_{2}$ receptor activation (Braff and Geyer 1980; McKenna et al. 1989; Meert et al. 1989; Pierce and Peroutka 1989; Buckholtz et al. 1990; Burris et al. 1991); second, by the recent finding of $5-\mathrm{HT}_{2}$ receptor abnormalities in postmortem schizophrenic brain (Mita et al. 1986; Arora and Meltzer 1991; Joyce et al. 1993; Laruelle et al. 1993; ); and third by the role 
of $5-\mathrm{HT}_{2}$ receptor antagonism of atypical neuroleptics such as clozapine and risperidone (Nyberg et al. 1993; and Meltzer et al. 1994).

In the present PET and FDG study we take advantage of the psilocybin model of psychosis that provides a unique basis to investigate the associations between serotonin receptor activation, acute psychotic symptom formation, and metabolic alterations in the living human brain. Positron emission tomography (PET) using [F-18]-fluorodeoxyglucose (FDG) enables one to explore directly the interactive organization of the human brain, via the coupling of cerebral glucose and neuronal activity (Phelps et al. 1979). Hence relationships between metabolic alterations and higher mental activity have begun to be examined in both normal and psychopathological conditions. With regard to schizophrenia, several PET studies have found absolute or relative metabolic hypofrontality in chronic schizophrenic patients, especially when frontal activation tasks were used (Buchsbaum et al. 1982, 1990; Farkas et al. 1984; Wolkin et al. 1985; Volkow et al. 1987; Siegel et al. 1993). A number of PET studies, however, could not confirm this hypofrontality finding, possibly because some of these studies investigated mainly subacute schizophrenics (Sheppard et al. 1983; Widen et al. 1983; Volkow et al. 1987; Wiesel et al. 1987). Other PET studies demonstrated a variety of abnormalities, including hypertemporality (DeLisi et al. 1989), a left-right asymmetry of metabolism (Gur et al. 1987a, 1987b), and increased (Brodie et al. 1984; Wolkin et al. 1985) or reduced (Sheppard et al. 1983; Buchsbaum et al. 1992; Siegel et al. 1993) metabolism in the basal ganglia. These inconsistencies have been attributed to the heterogeneity of patient selection, medication status, clinical state, and cognitive behavior of patients during PET investigations.

More recent studies of drug-naive and chronic schizophrenic patients in acute episodes have revealed a hyperfrontal metabolic pattern (Volkow et al. 1986; Cleghorn et al. 1989; Ebmeier et al. 1993; Parellada et al. 1994). The finding that acutely ill schizophrenic patients had more positive than negative symptoms (Cleghorn et al. 1989) suggests that overactivity of the frontal cortex could be an important pathophysiological manifestation of acute psychotic episodes. A frontostriatal dysfunction of sensory and cognitive information processing involving the thalamic filter theory has been advanced in schizophrenia (Carlsson and Carlsson, 1990). According to this model, a glutamatergic and/or dopaminergic neurotransmitter dysbalance in cortico-striato-thalamic (CST) feedback loops should theoretically lead to an opening of the thalamic filter and a subsequent sensory overload of the frontal cortex. Based on anatomical and pharmacological evidence, we have hypothesized that excessive activation of postsynaptic elements of the serotonergic projection sites to several components of the CST loops by psilocybin should also result in a disrup- tion of the thalamic gating mechanism and a sensory overflow of the frontal cortex associated with the sensory flooding and cognitive fragmentation seen in psilocybin and naturally occurring psychosis (Vollenweider, 1992).

\section{MATERIALS AND METHODS}

The study was approved by the Ethics Committee of the Psychiatric University Hospital of Zürich, and the use of psychoactive drugs by the Swiss Federal Health Office, Department of Pharmacology and Narcotics, Bern. The subjects were examined at the Research Department of the Psychiatric University Hospital of Zürich (PUK), the MRI Center of the University Hospital of Zürich, and the PET Department of the Paul Scherrer Institute Villigen (PSI).

\section{Subjects}

Fifteen healthy volunteers ( 8 males, 7 females) aged between 26 and 43 years (mean $\pm \mathrm{SD}=33.3 \pm 4.8$ ) were recruited from university and hospital staff. Written consent was obtained. The subjects were screened by psychiatric interview to ensure that they had neither personal nor family histories of major psychiatric disorders in first-degree relatives. Subjects with a history of illicit drug abuse were excluded from the study. The openness and neuroticism scales of the Freiburg Personality Inventory (FPI) (Fahrenberg et al. 1984) also were used as exclusion criteria (Table 1). Subjects were healthy according to physical examination, electrocardiogram, blood, and urine analysis. All subjects had normal MRI scans.

\section{Experimental Design}

Subjects were tested in an open study in two phases, a preliminary drug tolerance test phase (I) followed by a PET phase (II). The study was designed to explore the effects of three different conditions on cerebral metabolic rates of glucose (CMRglu) in a given subject under investigation. Thus in this study, a subject served as his or her own control to minimize interindividual variability of data.

The 15 subjects were told that they would receive on three different occasions at monthly intervals a baseline PET scan, and a second and third PET scan in combination with a stimulant (d-amphetamine) or a hallucinogenic drug (psilocybin or ketamine). The study was not done blinded. The subjects knew that they would receive a drug scan, but they did not know which of the three study drugs would be administered. Baseline and drug scans were performed in randomized order across subjects. Five of the subjects received psilocybin and 
Table 1. Demographic Features and Global Psychopathological Scores under Psilocybin

\begin{tabular}{ccccccccc}
\hline & & & \multicolumn{2}{c}{ Baseline Condition } & & \multicolumn{2}{c}{ Psilocybin Condition } \\
Volunteer \# & Sex & Age & $\begin{array}{c}\text { FPI } \\
\text { Openness }\end{array}$ & $\begin{array}{c}\text { FPI } \\
\text { Neuroticism }\end{array}$ & & $\begin{array}{c}\text { Psilocybin } \\
\text { (mg/kg) }\end{array}$ & $\begin{array}{c}\text { APZ } \\
\text { Global }\end{array}$ & $\begin{array}{c}\text { EPI } \\
\text { Global }\end{array}$ \\
\hline 1 & M & 35 & 10 & 3 & & 0.28 & 21 & 40 \\
2 & F & 31 & 9 & 3 & & 0.29 & 21 & 41 \\
3 & M & 42 & 10 & 1 & & 0.28 & 11 & 47 \\
4 & M & 36 & 7 & 7 & & 0.25 & 19 & 41 \\
5 & M & 39 & 5 & 3 & & 0.26 & 30 & 48 \\
6 & F & 30 & 8 & 6 & & 0.36 & 14 & 42 \\
7 & M & 45 & 6 & 2 & & 0.20 & 29 & 42 \\
8 & M & 27 & 10 & 1 & & 0.22 & 16 & 38 \\
9 & M & 33 & 7 & 2 & & 0.20 & 23 & 40 \\
10 & M & 34 & 8 & 3 & & 0.21 & 21 & 41 \\
Mean & & 35.3 & 8 & 3 & & 0.26 & 37 & 42 \\
SD & & 5.6 & 1.8 & 2 & & 0.05 & 12.6 & 3.1 \\
\hline
\end{tabular}

FPI (Freiburg Personality Inventory) scores for openness and neuroticism for 10 volunteers receiving psilocybin. Means and SD of normative data of healthy controls, sex, and age matched are for openness $6.8 \pm 2.8$ for males and $6.0 \pm 2.9$ for females and for neuroticism $5.5 \pm 3.5$ for males and $6.7 \pm 3.7$ for females. Psilocybin was administered in capsules (15-20 mg PO) 90 minutes before PET scanning. The APZ (Altered State of Consciousness) and EPI (Ego Pathology Inventory) global scores refer to the phase during PET investigation.

ketamine, five of the subjects received ketamine and $\mathrm{d}$-amphetamine, and five of the subjects received psilocybin and d-amphetamine.

This report focuses on the relation between psilocybin-induced cerebral metabolic alterations and psychotomimetic reactions such as hallucinations and ego disorders. The effects of amphetamine and ketamine will be reported elsewhere.

Based on previous studies of psilocybin-induced psychological reactions in healthy volunteers, the following psilocybin doses were selected to ensure psychotomimetic effects, such as changes of affect, illusions, hallucinations, and loosening of ego boundaries, over a period of 120 to 180 minutes: $15 \mathrm{mg}$ PO for subjects $<50$ $\mathrm{kg}$ body weight and $20 \mathrm{mg}$ PO for subjects $>51 \mathrm{~kg}$. Fasting subjects ingested capsules containing psilocybin (5 mg/ capsule) 90 minutes before FDG injection so that the FDG/PET measurement would coincide with the peak effect of the drug (Hasler et al. 1995).

\section{Substance}

Psilocybin (o-Phosphoryl-4-hydroxy-N,N-dimethyl-tryptamine) was obtained through the Swiss Federal Health Office (BAG), Department of Pharmacology and Narcotics, Bern, and prepared as capsules $(5 \mathrm{mg}$ ) at the Pharmaceutical Institute of the University of Bern, Switzerland.

\section{Psychometric Scales}

All subjects were examined before and immediately after each PET scan by an experienced psychiatrist (F.X.V.) to assess scores in baseline and drug conditions using the Ego Pathology Inventory (EPI) (Scharfetter 1981; Weber and Scharfetter 1984) and the inventory of the "Association for Methodology and Documentation in Psychiatry" (AMDP) (Arbeitsgemeinschaft für Methodik und Dokumentation in der Psychiatrie AMDP, 1981). From the AMDP inventory two total scores for manic-depression and schizophrenia (syndrome scores) and 12 subscale scores (Apathy, Hallucinatory-disintegration, Thought disorder, Mania, Depression, etc.) can be derived. The EPI reliably measures ego pathology and related behavior. The EPI yields a global score (EPIglo) and five subscale scores that measure Ego identity impairment, Ego demarcation, Ego consistency, Ego activity, and Ego vitality. The Ego identity subscale measures changes or loss of one's own identity in respect to gestalt, physiognomy, gender, geneological origin, and biography. The Ego demarcation subscale refers to one's uncertainty or lack in differentiating between ego and nonego spheres concerning the thought process, affective state, and body experience. The Ego consistency subscale comprises the dissolution, splitting and destruction in experiencing a coherent self, body, thought process, chain of feelings, and a structured external world. The Ego activity subscale refers to the deficit in one's own ability, potency or power for self-determined acting, thinking, feeling, and perceiving. The Ego vitality subscale includes the experience or fear of one's own death, of the fading away of liveliness, or of ruin of mankind or of the universe. Both construct and discriminant validity of the EPI inventory have been validated recently in schizophrenics and comparison patients by an extensive empirical study using confirmatory factor analysis (Scharfetter, 1995). 
In addition to the symptom checklist SCL-90-R (Derogatis 1977), the Altered States of Consciousness Questionnaire (APZ) (Dittrich 1985) was applied as a selfassessment inventory to evaluate drug effects. The APZ questionnaire consists of 72 items that yield a global score (APZglo) and three subscale scores (factors) measuring shifts in mood and changes in the experience of the self, ego, and environment in altered states of consciousness (ASC). The first subscale Oceanic boundlessness (Ozeanische Selbstentgrenzung, OSE) measures changes in the sense of time and derealization and depersonalization phenomena associated with a positive basic mood ranging from heightened feelings to sublime happiness. The second subscale Dread of ego dissolution (Angstvolle Ichauflösung, AIA) basically describes a disintegrative state that encompasses the loss of autonomy and self-control concerning the thought process and intentionality, decision making, intentional actions, and spontaneous movements. The AIA-associated changes in mood appear to be secondary and are characterized by paranoid feelings of endangerment, anxiety, arousal, and heightened attention to the surroundings, which appear to be strange and peculiar. The third subscale Visionary restructuralization (Visionäre Umstrukturierung; VUS) refers to an altered visual perception including elementary or complex (pseudo)hallucinations or visions, synesthetic phenomena, a change of meaning of various precepts, difficulties differentiating between reality and the dreaming experience, as well as difficulties in gaining and keeping survey of what is going on with oneself and the environment (Dittrich 1985). The three APZ dimensions have been shown to be independent of etiology, (e.g., the inducing factor(s) of ASC) (Dittrich et al. 1981, 1985).

\section{Phase I: Preliminary Drug Exposure}

To reduce risks and anxiety and to determine the time course of the onset and peak effects of each drug, subjects received a preliminary drug exposure in a recreational environment at the PUK. Upon arriving at the PUK Research Department, subjects completed the predrug symptom checklist SCL-90-R. In the subsequent drug session, subjects were examined by an experienced psychiatrist before and at regular intervals after substance administration to evaluate the onset and the psychological peak effects using the Ego Pathology (EPI) and the AMDP inventory. The Altered States of Consciousness questionnaire (APZ) also was completed at the end of the session (change score analysis). Scores on the EPI and AMDP inventory after drug conditions were compared to scores after baseline and to scores after placebo conditions of a separate gender- and age-matched control group.

\section{Phase II: PET Studies}

Each subject underwent at monthly intervals a baseline and two drug FDG-PET scans according to the group design of phase I. Upon arriving at the PSI PET Department (11:00 A.M.), subjects were examined using the AMDP and EPI rating scales. The predrug symptom checklist (SCL-90-R) also was completed. Following these baseline measures, psilocybin was administered. Drug pretreatment times were selected so peak effects would coincide with the beginning of the FDG-PET scan. Psilocybin was administered 90 minutes before FDG injection.

Psilocybin FDG-PET scans were performed in 10 volunteers using a CTI (Siemens 933/04-16) tomograph. The scanner measures seven contiguous planes (width, $8 \mathrm{~mm}$ ) simultaneously with an in-plane transaxial resolution of $8 \mathrm{~mm}$ (full width half-maximum) after image reconstruction. Before tracer administration, a transmission scan was performed using an external germanium $68 /$ gallium 68 ring source with the field of view parallel to and from 20 to $76 \mathrm{~mm}$ above the orbitomeatal line (OM line) and in a second position displacing the field of view $40 \mathrm{~mm}$ in the cranial direction. A "dynamic scan" procedure with a series of consecutive scans with increasing time duration was performed during the first 48 minutes after tracer infusion. This scan was followed by one 5-minute scan in the second position, 50 to $106 \mathrm{~mm}$ above the OM line ("static scan"). At each scan, seven planes were recorded simultaneously but, because of two planes overlapping after axial displacement, the total number of recorded planes was twelve. FDG was infused slowly through an arm vein over 3 minutes using an infusion pump simultaneously with the beginning of the dynamic scan. The mean administered FDG dose was $177.6 \mathrm{MBq}$ (107.3-244.2). Twenty-three arterial blood samples were collected from an indwelling radial artery catheter (Teflon, $0.8 \mathrm{~mm}$ ) to determine blood plasma radioactivity, glucose concentration, and drug levels. An urethane foam head holder was made for each subject to fix the subject's head parallel to the OM line and to allow repeated PET experiments in virtually the same head position.

Using planes from the last time point of the dynamic measurement, 43 to 48 minutes, and from the static measurement performed between 48 and 53 minutes after injection, a contiguous set of 12 planes was formed representing uptake in a volume with an axial field of view $112 \mathrm{~mm}$ long. The autoradiographic method described by Rhodes (Rhodes et al. 1983) was used to form parametric images of rCMRglu for each of the planes independently on a pixel-by-pixel basis.

The images were transformed into the standard stereotaxic space described by Talairach (Talairach and Tournoux 1988) using a combination of linear and nonlinear transformations after automatic localization of the AC-PC line. Feature localization was determined by 
intercomparison of the image volume with a set of standard templates (Friston et al. 1989, 1991).

After spatial standardization, a standardized set of regions of interest (ROIs) (5.6 to $10.4 \mathrm{~mm}$ ) using the Talairach coordinate system were placed symmetrically in cortical and subcortical regions in both hemispheres. The coordinates according to Talairach of the following ROIs were determined and drawn in a number of adjacent planes: frontomedial $(n=8)$ and frontolateral cortex $(n=$ $8)$; insula $(n=1)$; anterior $(n=1)$ and posterior $(n=1)$ cingulate; parietal cortex $(n=2)$; somatosensory cortex $(n=1)$; motor cortex $(n=1)$; temporal lateral $(n=4)$ and temporal medial cortex $(n=2)$; temporal pole $(n=1)$; occipital medial cortex including occipital medial anterior and posterior $(n=2)$; occipital lateral cortex $(n=2)$; caudate nucleus ( $n=3)$; putamen $(n=2)$; thalamus $(n=3)$; cerebellum $(n=3)$; and white matter $(n=2)$. For each plane one total image ROI was determined (Figure 1).

Because of the variable number of planes, the total interindividual number of ROIs varied from 88 to 94 for both brain hemispheres, but the intraindividual number of ROIs in the left and right hemispheres was always equal in a series of PET scans. The ROIs were determined either on the last frame of the dynamic sequence (45 minutes after tracer injection) or in the static image obtained in the second head position. For each time frame, the ROI value was determined, decay corrected, and expressed in $\mathrm{Bq} / \mathrm{ml}$. In addition to the individual ROI values, ROIs in adjacent planes were pooled. Furthermore, all ROIs defined in the frontal, temporal, and occipital cortex were pooled to a frontal, temporal, and occipital average.
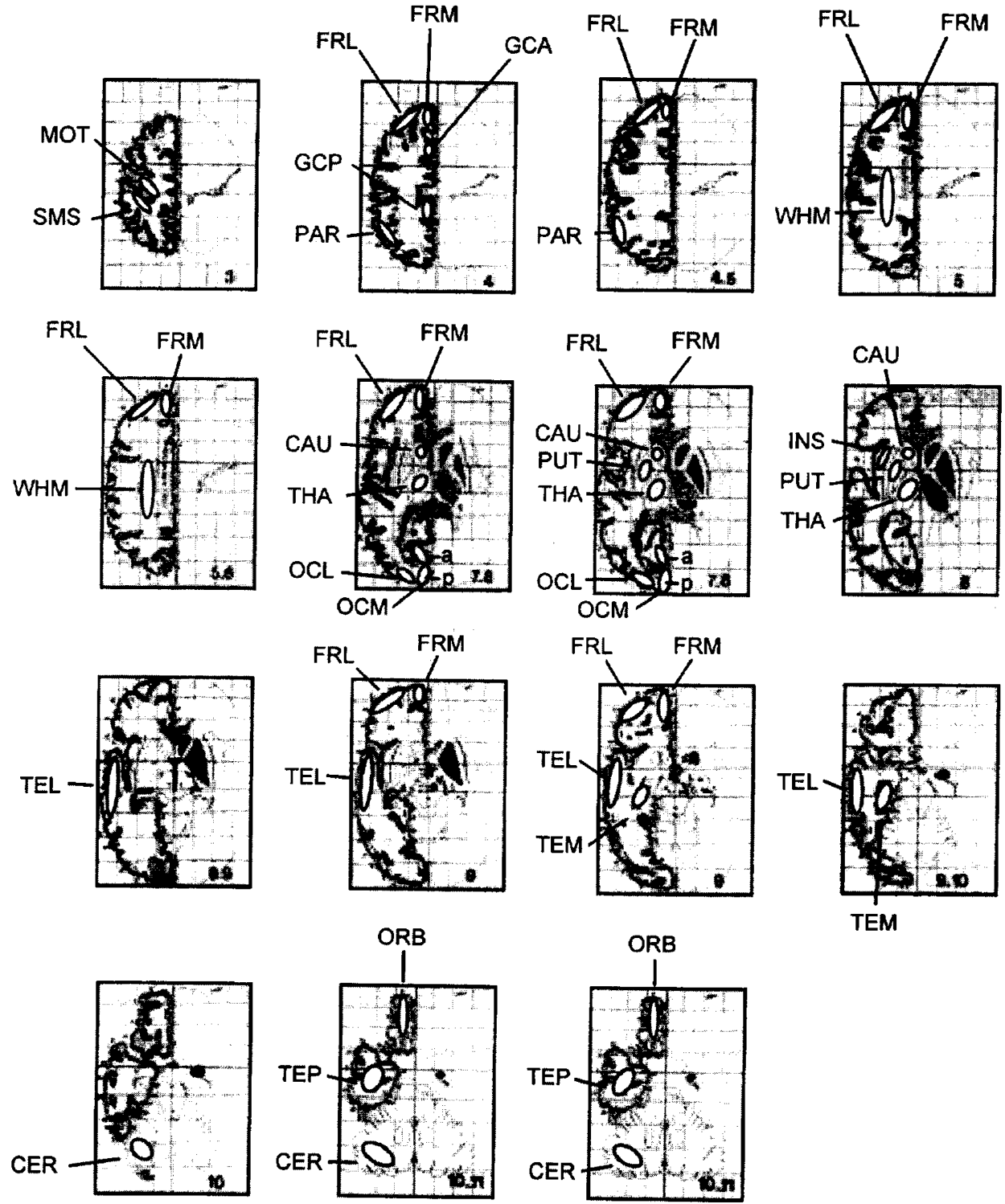

TEM
Figure 1. Coordinates determined using the Talairach coordinate system and superimposed after normalization on each PET scan. Talairach coordinates of cortical and subcortical ROIs: FRM, frontomedial cortex; FRL, frontolateral cortex; INS, insula; CGA, cingulate anterior; CGP, cingulate posterior; PAR, parietal cortex; SMS, somatosensory cortex; MOT, motor cortex; TEL, temporolateral cortex; TEM, temporomedial cortex; TEP, temporal pole; OCM, occipital medial cortex; OCL, occipitolateral cortex; CAU, caudate nucleus; PUT, putamen; THA, thalamus; CER, cerebellum; WHM, white matter.

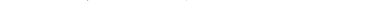


Regional glucose utilization was expressed as glucose metabolic rate $(\mu \mathrm{mol} / 100 \mathrm{~g} /$ minute $)$ and as relative glucose metabolic rate (ratio of absolute glucose metabolic rate to whole-brain mean glucose metabolic rate). Whole-brain mean glucose metabolic rate was calculated as the mean of three total image ROIs that cut through the basal ganglia. To compare metabolic data obtained in this study with data from schizophrenic patients, metabolic ratios such as the frontal to occipital ratio were calculated by dividing glucose metabolic rate in frontal cortex by glucose metabolic rate of the occipital cortex in the same hemisphere. Changes of absolute or relative metabolism and changes of metabolic ratios from a baseline to a psilocybin scan were assessed as percent difference from baseline.

\section{Plasma Psilocybin Assay}

Plasma psilocybin levels were measured using a highperformance liquid chromatography (HPLC) method with a sensitivity of less than $1 \mathrm{ng} / \mathrm{ml}$ for psilocybin (Hasler et al. 1995). During PET scanning the volunteers' plasma was collected using the cannula in the radial artery after $0,10,30,48$, and 54 minutes. All plasma samples were stored at $-20^{\circ} \mathrm{C}$ until analysis.

\section{Statistical Analyses}

All analyses were performed by computer using SAS and STATISTICA $/ \mathrm{w}^{\mathrm{TM}}$, version 4.5 (StatSoft $^{\mathrm{TM}}, 1993$ ). In this study, each subject served as his or her own control to minimize the effect of interindividual variation in metabolic rates and psychopathology scores. To examine differences in CMRglu and psychopathology scores between the baseline and psilocybin condition, the Wilcoxon matched pairs test was used. The Spearman correlation coefficient was used to evaluate correlations between significantly changed metabolic rates or ratios and psychopathology scores and also to examine to what extent psilocybin doses $(\mathrm{mg} / \mathrm{kg}$ ) were predictive of metabolic or psycho(patho)logical alterations. As no correction for the number of comparisons was made, the results should be regarded as exploratory rather than confirmatory.

\section{RESULTS}

\section{Psychopathology}

Psilocybin administration resulted in a psychotoxic syndrome, including disturbances of emotion, sensory perception, thought processes, reality appraisal, and ego functioning as measured by the APZ, EPI and AMDP rating scales (Figure 2). The psychotic symptoms appeared 20 to 30 minutes after oral administration of psilocybin and reached their peak effects after another 60 minutes, lasting for 1 to 2 hours. The symptoms had abated completely 5 to 6 hours after their initial appearance. The evolution of the syndrome was characterized by three phases. The initial phase, lasting 10 to $30 \mathrm{~min}-$ utes, was dominated by neurovegetative disturbances followed by a gradual increase of derealization and depersonalization phenomena, distortion of body image, and a feeling of inability to control emotional equilibrium.

During the second phase, the peak period, derealization, and depersonalization phenomena became fully developed. Alterations of the sense of time and space (OSE), disturbances of sensory perception (VUS), as well as loosening of ego boundaries (OSE, AIA, EPI), were

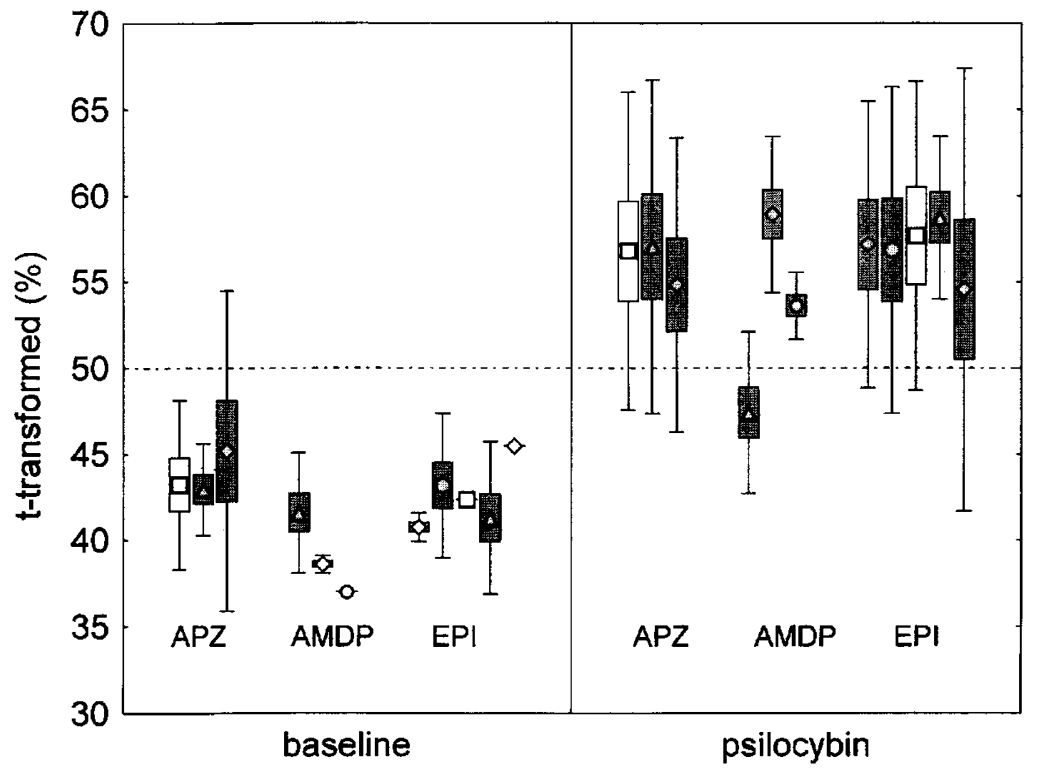

Figure 2. Mean ( \pm SD) scores ( $t$-transformed) of selected APZ, AMDP, and EPI subscales during baseline and psilocybin PET scanning. Bars indicate mean $\pm \mathrm{SE}$. With the exception of AIA $(p<.05)$ and apathy (NS), all psilocybin-induced psycho(patho)logical changes are significant at $p<.01$ (Wilcoxon). 
noted in all of the subjects. During this peak period, as PET scanning was started and subjects had their eyes closed, perceptual alterations included visual disturbances ranging from elementary ( $80 \%$ of subjects) to complex hallucinations $(70 \%$ of subjects), synesthesias such as "soundseeing" or "colorhearing", and distortions in the auditory and olfactory modes (VUS). Some of the subjects $(40 \%)$ reported recalling experiences of the recent and remote past associated with emotional disturbances and vivid scenery hallucinations. Auditory distortions were rather illusions than true hallucinations. Most of the subjects reported that they experienced a melody or rhythmic sound that was derived originally from the background noise such as the ventilation system of the PET scanner influencing their inner experience. Directed attention became difficult and subjects progressively lost their interest in the experimental situation. Thinking became sluggish and derealization phenomena sometimes influenced the content of thought. Derealization and loosening of ego boundaries were associ- ated in some of the subjects with a feeling of unreality and emotional alterations ranging from euphoria to a feeling of grandiosity or exaltation (high OSE scores), but other subjects reacted to derealization and depersonalization phenomena with misinterpretation of the experimental situation variously associated with heightened anxiety, suspiciousness, or paranoid ideation (high AIA scores). Initially experienced elation in psilocybin subjects could, however, also result in transient dysphoria and anxiety, especially when subjects realized that they were losing control over their thought. During this state of altered temporal and spatial relationships, ego functioning was impaired as measured by the global scale of the ego pathology inventory (Table 1; EPIglo). In particular, Ego identity and Ego-demarcation were impaired moderately. Higher ego pathology scores were found for Ego consistency and Ego activity, but virtually no changes from baseline were noted on the Ego vitality scale (Figure 2). During the terminal phase, psychological alterations gradually declined.

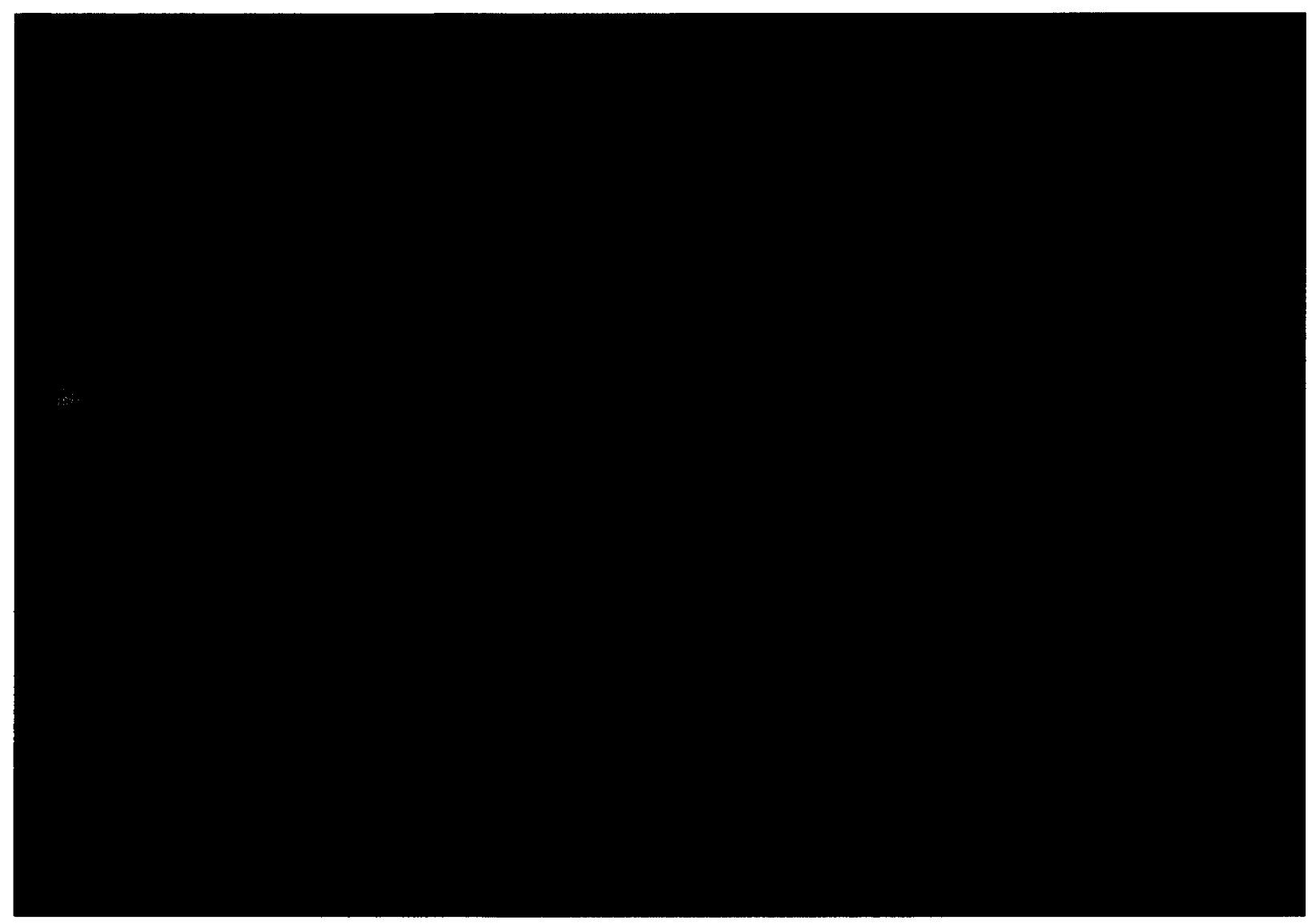

Figure 3. Two [18F]-FDG-PET images of the same subject under baseline (left) and psilocybin (right) conditions. Psilocybin administration (15-20 mg PO) resulted in a global increase of absolute cerebral metabolic rates of glucose (CMRglu: $\mu \mathrm{mol} /$ $100 \mathrm{mg} / \mathrm{min}$ ) with most marked increases in the frontomedial (FRM), frontolateral (FRL), cingulate anterior (CGA), and temporomedial cortices (TEM). Subcortical structures such as the caudate nucleus, putamen, and thalamus were less stimulated than cortical regions. No significant changes were observed in either temporal pole. Red $>$ orange $>$ yellow $>$ green $=1$ lowest value of CMRglu; note that the surface of the brain is not color-coded. 


\section{Absolute Whole-Brain and Regional Cerebral Metabolic Rates}

Psilocybin variously increased absolute cerebral metabolic rates of glucose (CMRglu) in most of the brain regions examined (Figure 3). Mean changes of absolute CMRglu ( $\mu \mathrm{mol} / 100 \mathrm{mg} / \mathrm{min}$ ) from baseline to psilocybin scan were assessed as percent from baseline. Wholebrain glucose metabolism was increased in all subjects (mean change: $19.9 \pm 4.8 \%, \mathrm{p}<.01$ ). As seen in Figure 4 , the highest increases of CMRglu were found bilaterally in the frontomedial (left/right: $23.5 \% / 25.6 \%$ ), frontolateral $(25.4 \% / 22.7 \%)$, anterior cingulate, temporomedial cortex $(22.9 \% / 27.1 \%)$, and thalamus $(21.9 \% / 25.0 \%)$. Smaller increases were found in the somatosensory $(9.7 \% / 19.1 \%)$, motor $(14.1 \% / 16.0 \%)$, occipitomedial cortex $(13.7 \% / 15.1 \%)$, and putamen $(21.0 \% / 15.5 \%)$. Pairwise comparison of the regional changes revealed that the absolute increases in the frontal (average of frontomedial and lateral cortex) and temporomedial cortex were significantly higher than in the left and right occipital cortex (average of occipitomedial and lateral cortex) and right putamen $(p<.05)$. Similarly, increases in the anterior cingulate cortex were significantly higher than in the left somatosensory cortex, right putamen, and occipital cortex $(p<.01)$.

Increases of CMRglu in the frontal $(p<.04)$, temporolateral $(p<.05)$, and motor $(p<.02)$ cortex in the left hemisphere, and increases of CMRglu in the frontal $(p<$ .04 ) and posterior cingulate cortex in the right hemisphere significantly correlated with the amount of psilocybin administered per kilograms of body weight ( $\mathrm{mg} / \mathrm{kg}$ po).

In the baseline condition, a left-greater-than-right asymmetry of glucose metabolic rate was found in the frontolateral $(p<.01)$ and sensorimotor cortex $(p<.01)$. Although psilocybin significantly increased the leftgreater-than-right asymmetry seen in the frontolateral cortex $(p<.01)$, the sensorimotor asymmetry was abolished by psilocybin.

\section{Cortico-cortico and Cortico-subcortical Metabolic Ratios}

To look for a hyper- or hypofrontal pattern of metabolism, ratios of metabolic rates between brain regions were calculated (Table 2). Mean changes of metabolic ratios from a baseline to a psilocybin scan were assessed as percent change from baseline ( $\%$ left $/ \%$ right). The frontomedial-occipitomedial ratio was increased significantly in both hemispheres $(9.7 \% / 9.5 \%)$, indicating a hyperfrontal pattern. The ratio between the frontolateral and temporolateral cortex was changed slightly, but significantly in both hemispheres $(3.8 \% /-2.1 \%)$. Of the cortical-subcortical ratios the ratio between the frontomedial/frontolateral cortex and putamen was increased significantly only in the right hemisphere $(9.7 \%$ and $7.3 \%$ ). Taken together, there were more significant increases of metabolic ratios in the right than in the left hemisphere (right:left ratio $=5: 3$ ).

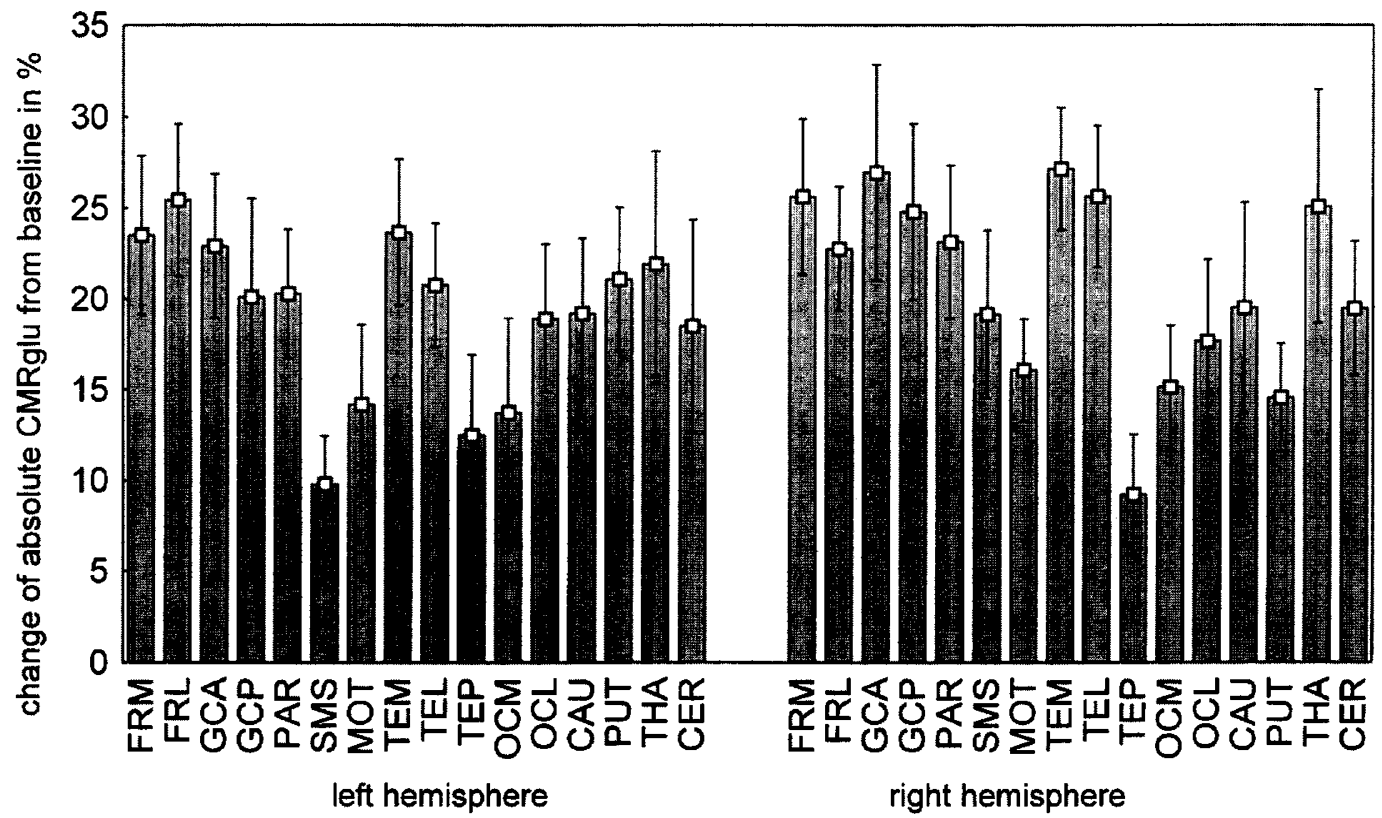

Figure 4. Effects of psilocybin on absolute CMRglu $(n=10$; mean \pm SE). With the exception of the temporal pole $(p=\mathrm{NS})$, all increases are significant at the $\mathrm{p}<.05-.01$ level. FRM, frontomedial cortex; FRL, frontolateral cortex; CGA, cingulate anterior; CGP, cingulate posterior; PAR, parietal cortex; SMS, somatosensory cortex; MOT, motor cortex; TEL, temporolateral cortex; TEM, temporomedial cortex; OCM, occipitomedial cortex; OCL, occipitolateral cortex; CAU, caudate nucleus; PUT, putamen; THA, thalamus; CER, cerebellum. 
Table 2. Metabolic Gradients (ratios) under Baseline and Psilocybin Conditions

\begin{tabular}{|c|c|c|c|c|c|c|c|c|c|c|}
\hline \multirow{3}{*}{$\begin{array}{l}\text { Metabolic } \\
\text { Gradients } \\
\text { (ratios) }\end{array}$} & \multicolumn{4}{|c|}{ Baseline } & \multicolumn{5}{|c|}{ Psilocybin } & \multirow[b]{3}{*}{$p$ level } \\
\hline & \multicolumn{2}{|c|}{ Left $(n=10)$} & \multicolumn{2}{|c|}{ Right $(n=10)$} & \multicolumn{2}{|c|}{ Left $(n=10)$} & \multirow[b]{2}{*}{$p$ level } & \multicolumn{2}{|c|}{ Right $(n=10)$} & \\
\hline & Mean & SD & Mean & SD & Mean & SD & & Mean & SD & \\
\hline FM-TM & 1.32 & 0.13 & 1.39 & 0.18 & 1.31 & 0.07 & NS & 1.37 & 0.13 & NS \\
\hline FM-TL & 1.08 & 0.07 & 1.10 & 0.08 & 1.10 & 0.06 & NS & 1.10 & 0.05 & NS \\
\hline FM-OM & 1.03 & 0.09 & 1.06 & 0.13 & 1.12 & 0.07 & $<.05$ & 1.15 & 0.06 & $<.05$ \\
\hline FM-OL & 1.22 & 0.11 & 1.26 & 0.08 & 1.25 & 0.06 & NS & 1.35 & 0.13 & $<.05$ \\
\hline FM-PA & 1.06 & 0.06 & 1.10 & 0.07 & 1.08 & 0.04 & NS & 1.12 & 0.07 & NS \\
\hline FM-CA & 1.04 & 0.08 & 1.06 & 0.06 & 1.07 & 0.06 & NS & 1.13 & 0.17 & NS \\
\hline FM-PU & 1.03 & 0.10 & 1.02 & 0.07 & 1.05 & 0.11 & NS & 1.11 & 0.07 & $<.05$ \\
\hline FM-TH & 1.16 & 0.15 & 1.21 & 0.10 & 1.18 & 0.10 & NS & 1.23 & 0.08 & NS \\
\hline FL-TM & 1.31 & 0.14 & 1.33 & 0.16 & 1.32 & 0.05 & NS & 1.28 & 0.14 & NS \\
\hline FL-TL & 1.07 & 0.06 & 1.05 & 0.05 & 1.11 & 0.05 & $<.05$ & 1.02 & 0.04 & $<.05$ \\
\hline FL-OM & 1.03 & 0.09 & 1.01 & 0.12 & 1.14 & 0.09 & NS & 1.08 & 0.08 & NS \\
\hline FL-OL & 1.22 & 0.10 & 1.20 & 0.06 & 1.27 & 0.10 & $<.05$ & 1.26 & 0.12 & NS \\
\hline FL-PA & 1.05 & 0.04 & 1.04 & 0.04 & 1.10 & 0.05 & NS & 1.04 & 0.06 & NS \\
\hline FL-CA & 1.04 & 0.07 & 1.01 & 0.06 & 1.08 & 0.09 & $.06<p<.07$ & 1.05 & 0.17 & NS \\
\hline FL-PU & 1.03 & 0.09 & 0.97 & 0.05 & 1.06 & 0.09 & NS & 1.04 & 0.07 & $<.05$ \\
\hline FL-TH & 1.15 & 0.15 & 1.16 & 0.08 & 1.19 & 0.09 & NS & 1.15 & 0.09 & NS \\
\hline
\end{tabular}

Abbreviations: FM, frontomedial; FL, frontolateral; OM, occipitomedial; OL, occipitolateral; TM, temporomedial; TL, temporolateral; PA, parietal; $\mathrm{CA}$, nucleus caudatus; $\mathrm{PU}$, putamen; $\mathrm{TH}$, thalamus.

\section{Correlations between Psychological and Metabolic Changes}

To explore the relationship between psilocybin-induced reactions and metabolic alterations, the APZ, AMDP, and EPI scores for hallucinatory disturbances, ego, and thought disorders were correlated with changes of absolute metabolic rates of glucose or metabolic ratios.

The AMDP syndrome score for schizophrenia showed positive correlations with the increases of absolute CM-
Rglu in the left temporolateral cortex $(p<.03)$ and putamen $(p<.04)$. As seen in Table 3, the AMDP subscale score for Hallucinatory-disintegration (Hall), the APZ scores for VUS, including mainly items for illusions and hallucinations as well as the APZ scores for OSE, referring to derealization and depersonalization, showed negative correlations with the increase of the frontomedial-temporolateral ratio (Hall: $p<.008$; VUS: $p<.04$; OSE: $p<.003$ ) or the frontolateral-temporolat-

Table 3. Correlations between Psychopathology Scores and Change of Metabolic

Gradients under Psilocybin $(n=10)$

\begin{tabular}{|c|c|c|c|c|c|c|}
\hline & \multicolumn{3}{|c|}{ Left Hemisphere } & \multicolumn{3}{|c|}{ Right Hemisphere } \\
\hline & $\begin{array}{c}\text { Change of } \\
\text { Gradients } \\
p \text { level }\end{array}$ & Syndrome & $\begin{array}{c}\text { Correlation } \\
\text { (Spearman), } \\
p \text { Level }\end{array}$ & $\begin{array}{c}\text { Change of } \\
\text { Gradients } \\
p \text { Level }\end{array}$ & Syndrome & $\begin{array}{c}\text { Correlation } \\
\text { (Spearman), } \\
p \text { Level }\end{array}$ \\
\hline FM-OM & $<.05$ & Hall. (AMDP) & Inverse-U & $<.05$ & Hall. (AMDP) & Inverse-U \\
\hline FM-GA & NS & Identity (EPI) & +0.003 & NS & - & - \\
\hline FM-TM & NS & AIA (APZ) & +0.05 & NS & Identity (EPI) & +0.002 \\
\hline FM-TL & NS & $\begin{array}{l}\text { Hall. (AMDP) } \\
\text { VUS (APZ) } \\
\text { OSE (APZ) }\end{array}$ & $\begin{array}{l}-0.008 \\
-0.04 \\
-0.003\end{array}$ & NS & Demarc. (EPI) & +0.03 \\
\hline FL-TL & $<.05$ & $\begin{array}{l}\text { Hall. (AMDP) } \\
\text { OSE (APZ) }\end{array}$ & $\begin{array}{l}-0.05 \\
-0.01\end{array}$ & $<.05$ & - & - \\
\hline FL-PU & NS & Apathy (AMDP) & +0.0002 & $<.05$ & AIA (APZ) & +0.01 \\
\hline
\end{tabular}

Abbreviations: FM, frontomedial cortex; FL, frontolateral cortex; GA, cingulate anterior; CA, caudate nucleus; PU, putamen; TM, temporomedial cortex; TL, temporolateral cortex; OM, occipitomedial cortex; schizo, schizophrenic syndrome (AMDP syndrome score); hall., hallucinatory-disintegration (AMDP subscale score); identity, ego-identity impairment (EPI subscale score); AIA, dread of ego dissolution; VUS, visionary restructuralization; OSE, oceanic boundlessness. Significant changes of metabolic gradients are indicated by Wilcoxon's $p$. Values are not corrected for multiplicity of tests. 
eral ratio (Hall: $p<.05$; OSE: $p<.01$ ) in the left hemisphere. Neither of these scales showed a significant correlation with the absolute changes of CMRglu in the frontal or temporolateral cortex. Scores for Hallucinatory-disintegration also showed bilaterally an inverse U-relation with the frontomedial-occipitomedial ratio.

The APZ scores for AIA comprising items for an anxious ego dissolution correlated positively with the increase of absolute CMRglu in the anterior cingulate cortex $(p<.05)$ in both hemispheres. The AIA scores also correlated with the left frontomedial-temporomedial ratio $(p<.05)$ and the right frontolateral-putamen ratio $(p<.01)$. Of the ego pathology inventory, scores for Ego-identity impairment $(p<.04)$ and Ego-demarcation $(p<.04)$ showed a positive correlation with the increase of absolute CMRglu in the right frontomedial cortex. Scores for Ego-identity impairment also correlated positively with the change of the frontomedial-anterior cingulate ratio $(p<.003)$ in the left hemisphere and the frontomedial-temporomedial ratio $(p<.04)$ in the right hemisphere. The EPIglobal scores showed positive correlations with CMRglu in the left frontolateral cortex $(p<.008)$, right frontomedial cortex $(p<.03)$, and right cingulate posterior cortex $(p<.01)$.

\section{DISCUSSION}

\section{Psychopathology}

Psilocybin administration to the healthy volunteers in our study resulted in a psychosis-like syndrome that resembled in many ways acute schizophrenic experiences, but is different in other respects. Psilocybin produced changes in affect and mood (Isbell 1959; Hollister and Hartmann 1962; Malitz et al. 1965), alterations in the sense of time and space (Heimann 1963; Hill and Fischer 1973), illusions and hallucinations (Fischer et al. 1969; Hollister 1961; Tosi et al. 1968), and impaired ego functioning. Hallucinatory-disintegration and loss of self-control over thought processes and intentionality are highly reminiscent of acute schizophrenic decompensation (Rümmele and Gnirss 1961; Keeler 1965; Bowers and Freedman 1966; Martindale and Fischer 1977; Heimann 1986; Scharfetter 1987). In particular, the finding of heightened awareness associated with euphoria and/or visual hallucinations in psilocybin psychosis is in line with the notion that the earliest affective changes in schizophrenic patients often are pleasurable or exhilarating (Chapman 1966; Bowers 1968; Hermle et al. 1992; Gouzoulis et al. 1994) and that visual hallucinations occur significantly more often in acute than in chronic schizophrenic patients (McCabe et al. 1972; Freedman and Chapman, 1973; Gouzoulis et al. 1994). Emotional disturbances and thought disorganization appeared to be secondary to and influenced by derealization and depersonalization phenomena, especially when subjects were no longer able to distinguish internal processes from external ones. At the doses tested, this difficulty in reality appraisal and impairment of ego functioning was transient and occurred only in some of the subjects. Typically, psilocybin subjectsunlike schizophrenics-could recognize derealization and depersonalization phenomena as abnormal experiences and attribute them to the drug. Interindividual differences in these responses might have been due either to variations in dosage or personality trait (Fischer et al. 1970; Thatcher et al. 1970). Comparison of the ego pathology (EPI) scores (mean values) of the present study with EPI scores obtained in first-episode schizophrenic patients revealed that the dimensions Ego-consistency (forming a coherent frame of reference) and Ego-identity were impaired similarly in both conditions. Scores for the dimension Ego-activity (one's selfdetermined acting, thinking, feeling, and perceiving) and scores for Ego-demarcation were only half of the values seen in schizophrenic patients. Similarly, the dimension Ego-vitality was clearly less affected in psilocybin subjects than in schizophrenic patients (Scharfetter 1995). Taken together, the present findings support the notion that serotonergic agonists, such as psilocybin and LSD, can mimic some important aspects of schizophrenic psychoses (Claridge 1978; Leuner 1981; Fischman 1983), but that there also are differences (Hollister and Hartmann 1962; Thatcher et al. 1971; Parashos 1976).

\section{Metabolism and Serotonin}

The present PET data confirm the central hypothesis that psilocybin, a mixed serotonin $5-\mathrm{HT}_{2}$ and $5-\mathrm{HT}_{1}$ receptor agonist, leads to a hyperfrontal metabolic pattern associated with acute psychotic symptom formation. This hyperfrontality finding is in line with the observation that administration of mescaline, which more specifically acts on $5-\mathrm{HT}_{2}$ receptors, resulted in a predominant activation of the frontal cortex during mescaline-induced psychosis (Hermle et al. 1993). Significant and marked increases of cerebral blood flow (CBF) after LSD administration also have been found in the frontal and parietal cortices of the conscious rat brain (Goldman et al. 1975).

There is substantial evidence that both indoleamine (LSD, psilocybin) and phenylethylamine hallucinogens (mescaline, DOM) might mediate their psychological effects primarily through activation of $5-\mathrm{HT}_{2 \mathrm{~A}}$ (and 5- $\mathrm{HT}_{2 \mathrm{C}}$ ) receptors located on cortical interneurons (SandersBush et al. 1988; McKenna et al. 1989; Sadzot et al. 1989; Aghajanian 1994). A PET study using radiolabeled LSD found highest concentrations of $5-\mathrm{HT}_{2}$ receptors in the frontal and temporal cortices, lower levels in the parietal cortex and motor regions, intermediate levels in the basal ganglia, and very low levels in the thalamus (Wong et al. 1987). Thus it is possible to assume that the present metabolic findings might be related to excessive 
activation of $5-\mathrm{HT}_{2}$ receptors in the brain. Although in the present study the psilocybin-induced pattern of metabolic changes approximately corresponds with the $5-\mathrm{HT}_{2}$ receptor-rich brain regions, the metabolic changes cannot be interpreted as due only to $5-\mathrm{HT}_{2}$ receptor activation. In particular, the finding that the frontal cortex was metabolically two to three times more stimulated than the occipital cortex, despite their almost equal 5- $\mathrm{HT}_{2}$ receptor densities (Bivier et al. 1994), indicates that regulatory mechanisms and/or other neurotransmitter systems also are implicated.

The hyperfrontality finding can be interpreted in the light of the thalamic filter theory of schizophrenia (Carlsson and Carlsson, 1990), which suggests that disruption of cortico-striato-thalamic (CST) feedback loops controlling a thalamic filter function should theoretically lead to a sensory overload of the frontal cortex and its limbic relay stations. The marked metabolic stimulation of the frontal cortex, the anterior cingulate, the temporomedial cortex, and the thalamus seen in the present study is in line with such an interpretation, insofar that these regions are all components of the limbic CST loop. A similar activation pattern with a global increase of CMRglu and marked increases in the frontal cortex $(30 \%-$ $34 \%)$, cingulate anterior $(34 \%)$, temporal cortex $(16 \%$ $19 \%)$, thalamus $(22 \%-24 \%)$, and occipital cortex $(16 \%)$ was found in the ketamine model of psychosis (Vollenweider et al. in press).

But unlike psilocybin, at psychotomimetic doses ketamine is thought to block primarily N-methyl-D-aspartate (NMDA) receptors (Øye et al. 1991). Thus blockage of NMDA receptors located on cortical GABAergic neurons may be a major cause responsible for the global increase of cortical metabolism under ketamine (Drejer and Honoré, 1987), whereas inhibition of NMDA receptor mediated cortico-striatal neurotransmission might add to the marked frontocortical activation seen in the ketamine model of psychosis (Vollenweider et al. in press). The common hyperfrontality finding seen in both the psilocybin and ketamine model of psychoses suggests that metabolic hyperfrontality might be due to a common neurotransmitter dysbalance in cortico-striatal pathways. As $5-\mathrm{HT}_{2}$ and NMDA receptors have been located on GABAergic neurons in the frontal cortex (Aghajanian 1994; Olney et al. 1991), GABAergic neurons in cortico striatal pathways may provide a common anatomical substrate involved in the pathophysiology of psilocybin- and ketamine-induced metabolic hyperfrontality. On the other hand, both psilocybin and ketamine have been reported to activate either directly or indirectly the dopaminergic system. As activation of the dopaminergic pathways could theoretically lead to a disruption of the information flow in CST loops, the possibility remains that dopamine also contributes to the pathophysiology of hyperfrontality and acute psychotic symptom formations seen in both types of model psychoses (Da-
Prada et al. 1975; Kehr 1977; Meltzer et al. 1978, 1981; Hiramatsu et al. 1989).

\section{Hyperfrontality and Psychopathology}

In the present study, the global ego pathology score (EPIglo) correlated positively with the increase of absolute CMRglu that extended from the left frontolateral to the right frontomedial cortex. Similarly, the APZ scale AIA, which refers more to an anxious ego dissolution, showed a positive correlation with the increase of CMRglu in the anterior cingulate cortex. These findings are generally in line with our previous observation of a positive correlation between ego pathology scores and metabolic hyperfrontality in the ketamine model of psychosis (Vollenweider et al. in press). Moreover, scores for Ego-identity impairment and Ego-demarcation also showed (as previously reported for ketamine) a positive correlation with the increase of absolute CMRglu in the right frontomedial cortex, whereas Ego-identity impairment strongly correlated with the frontomedial-anterior cingulate ratio in the left hemisphere and the frontomedial-temporomedial ratio in the right hemisphere. Thus the present findings support our previous results suggesting that metabolic hyperfrontality might be related to ego disintegration and derealization phenomena, although functional alterations in related brain areas also might contribute to or disturb frontal lobe activity.

This interpretation is further supported by recent SPECT and PET findings indicating that hyperfrontality, rather than hypofrontality, is associated with acute psychotic symptom formation, particularly in acutely psychotic schizophrenics. For example, a hyperfrontal pattern of CBF (Ebmeier et al. 1993; Parellada et al. 1994) or increased frontal to parietal ratio of CMRglu was found under resting conditions and associated with positive psychotic symptoms in acute unmedicated first-episode schizophrenics (Cleghorn et al. 1989; Kaplan et al. 1993). Similarly, a hyperfrontal metabolic pattern (Ebmeier et al. 1993) and a positive correlation between the increase in cerebral blood flow in the right anterior cingulate cortex and a "disorganization" syndrome was found in unmedicated and medicated chronic schizophrenic patients in acute psychotic episodes (Ebmeier et al. 1993; Liddle et al. 1992b). A rightgreater-than-left metabolic hyperfrontality associated with derealization and depersonalization phenomena was found in the mescaline model of psychosis (Hermle et al. 1993). Thus the present observation of hyperfrontality in the psilocybin model corroborates similar findings with ketamine and mescaline. The common effect of these three drugs appears to parallel comparable metabolic changes associated with acute psychotic episodes in schizophrenics and contrasts with the hypofrontality seen in chronic schizophrenic patients. 
The finding of a correlation between impaired ego functioning and metabolic hyperfrontality is in line with clinical findings and theories of schizophrenia, suggesting that the functional integrity of the frontal and anterior cingulate cortex might be a critical component in the pathophysiology of psychotic symptom formation (Robbins, 1990; Benes, 1993). The frontomedial cortex has been shown to be involved in sustained attention implicated in action and thought processes, in memory functions (Petrides et al. 1993; Dolan et al. 1994), and in the maintenance of goal directed behavior (Fuster, 1989). The frontolateral cortex has been associated in cross association and synthesis of sensory modalities, in structuring of episodes, as well as in judging and interpretation of visual and spatial information about the internal and external reality (Milner et al. 1985; Pribram 1991; Wilson et al. 1993). The anterior cingulate cortex, which receives input from the dorsolateral prefrontal cortex, the parietal cortex, and limbic structures, is involved in several functional networks implicated in attention, motivation, memory, emotion, and movement. Thus the anterior cingulate is thought to integrate, rather than to mediate, prefrontally and limbically processed functions.

Nevertheless, there also is some evidence that the anterior cingulate might be a primary site for directing attention (Cohen et al. 1987; Petersen et al. 1988; Posner and Petersen, 1990). Direct electrical stimulation of the anterior cingulate cortex can lead to a spectrum of psychosensory and behavioral phenomena, including affective changes, fear (Meyer et al. 1973), euphoria (Talairach et al. 1973), confusion and hallucinations (Escobedo et al. 1969), involuntary vocalization, and changes in speech (Meyer et al. 1973). In view of these findings, the association between derealization phenomena, ego pathology, and hypermetabolism in the anterior cingulate found in our subjects may be due to a direct disruption of prefrontally processed functions and/or to a dissociation of the functional interaction between the prefrontal cortex, the anterior cingulate, and their projection sites. In particular, sensory overload of the prefrontal cortex could lead to a dissociation of object and spatial processing domains within the prefrontal cortex, which in turn could lead to the mismatch of internal and external reality, the change of the sense of time and space, and the impairment of ego functioning seen in psilocybin subjects. In respect to the present hyperfrontality finding it is interesting to note that cingulotomy has been reported to have the best uniform outcome in patients with affective and anxiety disorders and second best in obsessive-compulsive disorders and schizophrenia patients (Gonzalez 1980; Ballantine et al. 1987).

The three rating scales (Hallucinatory-disintegration, VUS, and OSE) that overlap in their item pool measuring derealization and depersonalization phenomena showed a negative correlation with the increase of the fronto-temporal ratios in the left hemisphere. This finding suggests that neuronal dysfunctions in remote areas of the frontal cortex such as the temporal lobe are critically involved in the pathophysiology of ego disorders and hallucinations. This interpretation is supported by the fact that the AMDP syndrome score for Schizophrenia correlated positively with the increase of CMRglu in the left temporal lobe. Likewise, a positive (Liddle et al. 1992b) and negative (Ebmeier et al. 1993) correlation between Reality distortion and CBF in the temporomedial cortex was found in chronic schizophrenic patients in acute episodes, but it has been suggested that the discrepancy in the direction of these correlations is due to different drug regimens (Ebmeier et al. 1993).

The Schizophrenic syndrome and the global EPI score correlated also bilaterally with the increase of CMRglu in the putamen and in the left caudate nucleus. These results are in line with the findings of a positive correlation between Liddle's Reality distortion factor and increased CBF in the left ventral striatum (Liddle et al. 1992a) and caudate nucleus in unmedicated and medicated chronic schizophrenic patients during acute psychotic episodes. A significant correlation between improvement in acute psychotic symptoms and decrease in left caudate glucose metabolism also was found in unmedicated chronic schizophrenics (Buchsbaum et al. 1987). Increased CMRglu in the left caudate nucleus (Wiesel et al. 1987) and increased CBF in the left globus pallidus (Early et al. 1987) and the right putamen (Ebmeier et al. 1993) was reported in drug-free schizophrenic patients. The variability of correlations and metabolic changes in the basal ganglia might possibly be due to different methodological approaches or to partial volume effects among the caudate, putamen, and globus pallidus. Taken together, the correlations in the psilocybin model of psychosis appear to parallel comparable metabolic changes in the basal ganglia associated with acute psychotic symptoms in unmedicated chronic or first-episode schizophrenic patients.

In conclusion, the present study suggests that the psilocybin-induced metabolic hyperfrontality and alterations in the left temporal lobe, the occipital cortex, and the basal ganglia relate to ego disintegration and hallucinations. The present hyperfrontality finding may be of particular importance because it is consistent with the recent hyperfrontality finding in acutely ill schizophrenic patients and contrasts with the hypofrontality finding in chronic schizophrenics. In combination with previous studies, the present results support the notion that the psilocybin model of psychosis provides a heuristic basis to investigate the role of $5-\mathrm{HT}_{2}$ receptor activation in the pathophysiology of schizophrenia. The possibility that $5-\mathrm{HT}_{2}$ receptor activation by psilocybin could lead either directly or indirectly to increased dopaminergic activity is an issue that needs to be further investigated. 


\section{ACKNOWLEDGMENTS}

We gratefully acknowledge the use of the SPM image analysis system, which was made available to us by courtesy of Dr. R. Frackowiak. We also are grateful to the Department of Radiopharmacy of the Paul Scherrer Institute through which the radiotracer FDG was obtained. We especially thank Professor R. Brenneisen of the Pharmaceutical Institute of the University of Bern for preparing the psilocybin capsules, Dr. T. Huber, Department of Inner Medicine, PUK, for the somatic investigations of volunteers, and Dr. M.F.I. Vollenweider-Scherpenhuyzen, Institute of Anesthesiology, University Hospital Zürich, for her helpful comments on the manuscript. This study was financially supported in part by the Swiss National Research Foundation (32-28746.90).

\section{REFERENCES}

Aghajanian GK (1994): LSD and phenethylamine hallucinogens: Common sites of neuronal action. In Pletscher A, Ladewig D (eds), Fifty Years of LSD. New York, The Parthenon Publishing Group, pp 27-41

Arbeitsgemeinschaft für Methodik und Dokumentation in der Psychiatrie (AMDP) (1981): Das AMDP-System. Manual zur Dokumentation psychiatrischer Befunde. Berlin, Springer-Verlag

Arora RC, Meltzer HY (1991): Serotonin 2 (5-HT2) receptor binding in the frontal cortex of schizophrenic patients. J Neural Transm Gen Sect 85:19-29

Ballantine HT, Bouckoms AJ, Thomas EK, Giriunas IE (1987): Treatment of psychiatric illness by stereotactic cingulotomy. Biol Psychiatr 22:807-817

Benes FM (1993): Neurobiological investigations in cingulate cortex of schizophrenic brain. Schizophr Bull 19:537-549

Bivier F, Goldman S, Luxen A, Monclus M, Forestini M, Mendlewicz J, Lotstra F (1994): Multicompartment study of fluorine-18 altanserin binding to brain 5HT2 receptors in humans using positron emission tomography. Eur J Nucl Med 21:937-946

Bowers MB (1968): Pathogenesis of acute schizophrenic psychosis. Arch Gen Psychiatr 15:240-248

Bowers MB, Freedman DX (1966): "Psychedelic" experiences in acute psychoses. Arch Gen Psychiatr 15:240-248

Braff DL, Geyer MA (1980): Acute and chronic effects on rat startle: data supporting an LSD-rat model of schizophrenia. Biol Psychiatr 15:909-916

Brodie JD, Christman DR, Corona JF, Fowler JS, Gomez Mont F, Jaeger J, Micheels PA, Rotrosen J, Russell JA, Volkow ND, Wickler A, Wolf AP, Wolkin A. (1984): Patterns of metabolic activity in the treatment of schizophrenia. Ann Neurol 15 Suppl S166-S169

Buchsbaum MS, Ingvar DH, Kessler R. (1982): Cerebral glucography with positron tomography: Use in normal subjects and in patients with schizophrenia. Arch Gen Psychiatr 39:251-259

Buchsbaum MS, Wu JC, DeLisi LE, Holcomb HH, Hazlett E, Cooper-Langston K, Kessler R (1987): Positron emission tomography studies of basal ganglia and somatosensory cortex neuroleptic drug effects: differences between nor- mal controls and schizophrenic patients. Biol Psychiatr 22:479-494

Buchsbaum MS, Nuechterlein KH, Haier RJ, Wu J, Sicotte N, Hazlett E, Asarnow R, Potkin S, Guich S (1990): Glucose metabolic rate in normals and schizophrenics during the continuous performance test assessed by positron emission tomography. Br J Psychiatr 156:216-227

Buchsbaum MS, Potkin SG, Siegel BVJ, Lohr J, Katz M, Gottschalk LA, Gulasekaram B, Marshall JF, Lottenberg S, Teng CY, Bunney WE, Abel L, Plon L (1992): Striatal metabolic rate and clinical response to neuroleptics in schizophrenia. Arch Gen Psychiatr 49:966-974

Buckholtz NS, Zhou DF, Freedman DX, Potter WZ (1990): Lysergic acid diethylamide (LSD) administration selectively downregulates serotonin 2 receptors in rat brain. Neuropsychopharmacology 3:137-148

Burris KD, Breeding M, Sander-Bush E (1991): (+)Lysergic acid diethylamide, but not its nonhallucinogenic congeners, is a potential serotonin $5 \mathrm{HT}_{1 \mathrm{C}}$ receptor agonist. J Pharmacol Exp Ther 258:891-896

Carlsson M, Carlsson A (1990): Schizophrenia: A subcortical neurotransmitter imbalance syndrome? Schizophren Bull 16:425-432

Chapman J (1966): The early symptoms of schizophrenia. Br J Psychiatry 112:225-251

Claridge G (1978): Animal models of schizophrenia: The case for LSD-25. Schizophren Bull 4:186-209

Cleghorn JM, Garnett ES, Nahmias C, Firnau G, Brown GM, Kaplan R, Szechtman H, Szechtman B (1989): Increased frontal and reduced parietal glucose metabolism in acute untreated schizophrenia. Psychiatry Res 28:119-133

Cohen RM, Semple WE, Gross M, Nordahl TE, DeLisi LE, Holcomb HH, Morihisa JM, Pickar D (1987): Dysfunction in an prefrontal substrate of sustained attention in schizophrenia. Life Sci 40:2031-2039

DaPrada M, Saner A, Burkhard WP, Bartholini G, Pletscher A (1975): Lysergic acid diethylamide: Evidence for a stimulation of cerebral dopamine receptors. Brain Res 94:67-73

DeLisi LE, Buchsbaum MS, Holcomb $\mathrm{HH}$, Langston $\mathrm{KC}$, King AC, Kessler R, Pickar D, Carpenter WT, Morihisa JM, Magolin R, Weinberger DR (1989): Increased temporal lobe glucose use in chronic schizophrenic patients. Biol Psychiatr 25:835-851

Derogatis LR (1977): SCL-90. Johns Hopkins University School of Medicine, Chicago

Dittrich A (1985): Ätiologie-unabhängige Strukturen veränderter Wachbewusstseinszustände. Stuttgart, Ferdinand Enke Verlag

Dittrich A, von Arx S, Staub S (1981): International study on altered states of consciousness (ISASC). Schweiz Z Psychol Anw 40:189-200

Dittrich A, von Arx S, Staub S (1985): International study on altered states of consciousness (ISASC). Summary of the results. Germ J Psych 9:319-339

Dolan RJ, Bench CJ, Brown RG, Scott LC, Frackowiak RSJ (1994): Neuropsychological dysfunction in depression: the relationship to regional cerebral blood flow. Psychol Med 24:849-857

Drejer J, Honoré T (1987): Phencyclidine analogues inhibit 
NMDA-stimulated [3H]GABA release from cultured cortex neurons. Eur J Pharmacol 143:287-290

Early TS, Reiman EM, Raichle ME, Spitznagel EL (1987): Left globus pallidus abnormality in never-medicated patients with schizophrenia. Proc Natl Acad Sci USA 84:561-563

Ebmeier KP, Blackwood DHR, Murray C, Souza V, Walker M, Doughall N, Moffoot APR, O'Carroll RE, Goodwin GM (1993): Single-photon emission computed tomography with $99 \mathrm{mTc}$-Exametazime in unmedicated schizophrenic patients. Biol Psychiatr 33:487-495

Escobedo F, Fernandez-Guardiola A, Solis G (1969): The corpus callosum, cingulate gyrus, septum pellucidum, spetal area and fornix. In Vinken PJ, Bruyn GW (eds), Handbook of Clinical Neurology. Amsterdam, Elsevier, pp 758-775

Fahrenberg J, Hampel R, Selg H (1984): Das Freiburger Persönlichkeitsinventar FPI. Göttingen, Hogrefe

Farkas T, Wolf AP, Jaeger J, Brodie JD, Christman DR, Fowler JS (1984): Regional brain glucose metabolism in chronic schizophrenia. A positron emission transaxial tomographic study. Arch Gen Psychiatr 41:293-300

Fischer R, Hill RM, Warshay D (1969): Effects of psychodysleptic drug psilocybin on visual perception. Changes in brightness preference. Experientia 25:166-169

Fischer R, Kappeler T, Wisecup P, Thatcher K (1970): Personality trait dependent performance under psilocybin. Dis Nerv Syst 31:92-101

Fischman LG (1983): Dreams, hallucinogenic drug states, and schizophrenia: a psychological and biological comparison. Schizophrenia Bull 9:73-94

Freedman B, Chapman LJ (1973): Early subjective experiences in schizophrenic episodes. J Abnorm Psychol $82: 46-54$

Friston KJ, Passingham RE, Nutt JG, Heather JD, Sawle GV, Frackowiak RS (1989): Localisation in PET images: direct fitting of the intercommissural (AC-PC) line. J Cereb Blood Flow Metab 9:690-695

Friston KJ, Frith CD, Liddle PF, Frackowiak RS (1991): Plastic transformation of PET images. J Comput Assist Tomogr 15:634-639

Fuster JM (1989): The Prefrontal Cortex. New York, Raven Press

Gaddum JH, Hammeed KA (1954): Drugs which antagonize 5-hydroxytryptamine. Br J Pharmacol 9:240-248

Goldman H, Fischer R, Nicolov N, Murphy S (1975): Lysergic acid diethylamide affects blood flow to specific areas of the conscious rat brain. Experientia 31:328-330

Gonzalez ER (1980): Treating the brain by cingulotomy. JAMA 244:2141-2147

Gouzoulis E, Hermle L, Sass H (1994): Psychedelische Erlebnisse zu Beginn produktiver Episoden endogener Psychosen. Nervenarzt 65:198-201

Gur RE, Resnick SM, Alavi A, Gur RC, Caroff S, Damm R, Silver FL, Seykin AJ, Chawluk JB (1987a): Regional brain function in schizophrenia I. A positron emission tomography study. Arch Gen Psychiatr 44:119-125

Gur RE, Resnick SM, Gur RC, Alavi A, Caroff S, Kushner M, Reivich M (1987b): Regional brain function in schizophrenia. II. Repeated evaluation with positron emission tomography. Arch Gen Psychiatr 44:126-129
Hasler F, Bourquin D, Brenneisen RM, Bär T, Vollenweider FX (1995): Pharmacokinetic profiles of oral and intravenous psilocybin. SOFT pp. 14

Heimann H (1963): Beobachtungen über gestörtes Zeiterleben in der Modellpsychose. Schweiz Med Wschr 93: 1703-1706

Heimann H (1986): Models of experience and behavior in psychotic disorders. Pharmacopsychiat 19:128-133

Hermle L, Spitzer M, Borchardt D, Gouzoulis E.(1992): Beziehungen der Modell-bzw. Drogenpsychosen zu schizophrenen Erkrankungen. Fortschr Neurol Psychiat 60: 383-392

Hermle L, Fünfgeld M, Oepen G, Botsch H, Borchard D, Gouzoulis E, Fehrenbach RA, Spitzer M (1993): Mescaline-induced psychopathological, neuropsychological, and neurometabolic effects in normal subjects: Experimental psychosis as a tool for psychiatric research. Biol Psychiatr 32:976-991

Hill RM, Fischer R (1973): Induction and extinction of psilocybin induced transformations of visual space. Pharmakopsychiatr Neuropsychopharmakol 6:258-263

Hiramatsu M, Cho AK, Nabeshima T (1989): Comparison of the behavioral and biochemical effects of the NMDA receptor antagonists, MK-801 and phencyclidine. Eur J Pharmacol 166:359-366

Hofmann A (1968): Psychotomimetic agents. In Burger A (ed.), Chemical Constitution and Pharmacodynamic Action. New York, M. Dekker, pp. 169-235

Hollister LE (1961): Clinical, biochemical and psychologic effects of psilocybin. Arch Int Pharmacodyn 42-52

Hollister LE, Hartmann AM (1962): Mescaline, lysergic acid diethylamid and psilocybin: Comparison of clinical syndromes, effects on color perception and biochemical measures. Comp Psychiat 3:235-241

Isbell H (1959): Comparison of reactions induced by psilocybin and LSD-25 in man. Psychopharmacologia 1:29-38

Joyce IN, Shane A, Lexow N, Winokur A, Casanova M, Kleinmann JE (1993): Serotonin uptake sites and serotonin receptors are altered in the limbic system of schizophrenics. Neuropsychopharm 8:315-336

Kaplan RD, Szechtman H, Franco S, Szechtman B, Nahmias C, Garnett ES, List S, Cleghorn JM (1993): Three clinical syndromes of schizophrenia in untreated subjects: relation to glucose activity measured by positron emission tomography (PET). Schizophr Res 11:47-54

Keeler MH (1965): Similarity of schizophrenia and the psilocybin syndrome as determined by objective methods. Int J Neuropsychiatry 1: 630-634

Kehr W (1977): Effect of lysuride and other ergot derivatives on monoaminergic mechanism in rat brain. Eur J Pharmacol 41:261-273

Laruelle M, Abi-Dargham A, Casanova F, Toti R, Weinberger DR, Kleinman JE (1993): Selective abnormalities of prefrontal serotonergic receptors in schizophrenia. Arch Gen Psychiatr 50:810-818

Leuner H (1981): Halluzinogene: Psychische Grenzzustände in Forschung und Therapie. Bern, Hans Huber

Liddle PF, Friston KJ, Frith CD, Frackowiak RSJ (1992a): Cerebral blood flow and mental processes in schizophrenia. J R Soc Med 85:224-227 
Liddle PF, Friston KJ, Frith CD, Hirsch SR, Frackowiak RSJ (1992b): Patterns of cerebral blood flow in schizophrenia. Br J Psychiat 160:179-186

Malitz S, Esecover H, Wilkens B, Hoch PH (1965): Some observations of psilocybin, a new hallucinogen, in volunteer subjects. Psychopharmacology 8-17

Martindale C, Fischer R (1977): The effects of psilocybin on primary process content in language. Confin Psychiatr 20:195-202

McCabe MS, Fowler RC, Cadoret RJ, Winokur G (1972): Symptom differences in schizophrenia with good and poor progosis. Am J Psychiatry 128:1239-1243

McKenna DJ, Nazarali AJ, Hoffman AJ, Nichols DE, Mathis CA, Saavedra JM (1989): Common receptors for hallucinogens in rat brain: a comparative autoradiographic study using $\left[{ }^{125} \mathrm{I}\right] \mathrm{LSD}$ and $\left[{ }^{125} \mathrm{I}\right] \mathrm{DOI}$, a new psychotomimetic radioligand. Brain Res 476:45-56

Meert TF, de Haes P, Janssen PA (1989): Risperidone (R 64 766), a potent and complete LSD antagonist in drug discrimination by rats. Psychopharmacology (Berlin) 97: 206-212

Meltzer HY, Fessler RG, Simonovic M, Fang VS (1978): Stimulation of rat prolactin secretion by indolealkylamine hallucinogens. Psychopharmacology 56:255-259

Meltzer HY, Sturgeon RD, Simonovic M, Fessler RG (1981): Phencyclidine as an indirect dopamine agonist. In Domino EF (ed), PCP (Phencyclidine): Historical and Current Perspectives. Ann Arbor, MI, NPP Books, pp. 207-242

Meltzer HY, Lee MA, Ranjan R (1994): Recent advances in the pharmacotherapy of schizophrenia. Acta Psychiatr Scand 90: 95-101

Meyer G, Mc Elhaney M, Martin W, McGraw CP (1973): Stereotactic cingulotomy with results of acute stimulation and serial psychological testing. In Laitinen LV, Livingston KE (eds), Surgical Approaches in Psychiatry. Baltimore, University Park Press, pp. 39-58

Milner B, Pertrides M, Smith ML (1985): Frontal lobes and the temporal organisation of memory. Human Neurobiol 4:137-142

Mita T, Hananda S, Nishino N, Kuno T, Nakai H, Yamdori T, Mizoi Y, Tanaka C (1986): Decreased serotonin S2 and increased dopamine D2 receptors in chronic schizophrenics. Biol Psychiatry 21:1407-1414

Nyberg S, Farde L, Eriksson L, Halldin C, Eriksson B (1993): $5-\mathrm{HT}_{2}$ and $\mathrm{D} 2$ dopamine receptor occupancy in the living human brain-A PET study with risperidone. Psychopharmacology (Berlin) 110:265-272

Olney JW, Labruyere J, Wang G, Wozniak DF, Price MT, Sesma MA (1991): NMDA antagonists neurotoxicity: mechanism and prevention. Science 254:1515-1518

Øye I, Hustveit O, Maurset A, Ratti Moberg E, Paulsen O, Skoglund LA (1991): The chiral forms of ketamine as probes for NMDA-receptor function in humans. In Kameyama T, Nabeshima T, Domino EF (eds), NMDA Receptor Related Agents: Biochemistry, Pharmacology and Behavior. Ann Arbor, MI, NPP Books, pp. 381-389

Parashos AJ (1976): The psilocybin-induced "state of drunkenness" in normal volunteers and schizophrenics. Behav. Neuropsychiatry 8:83-86
Parellada E, Catafau AM, Bernardo M, Lomeña F, GonzálezMonclús E, Setoain J (1994): Prefrontal dysfunction in young acute neuroleptic-naive schizophrenic patients: a resting and activation SPECT study. Psychiatr Res Neuroimaging 55:131-139

Petersen SE, Fox PT, Posner MI, Mintrun M, Raichle ME (1988): Positron emission tomographic studies of the cortical anatomy of single word processing. Nature 331: $585-589$

Petrides M, Alivisatos B, Meyer E, and Evans AC (1993): Functional activation of the human frontal cortex during the performance of working memory task. Proc Natl Acad Sci USA 90:878-882

Phelps ME, Huang SC, Hoffman EJ, Selin C, Sokoloff L, Kuhl DE (1979): Tomographic measurement of local cerebral glucose metabolic rate in humans with [F18]2-fluoro-2deoxy-D-glucose: Validation of method. Ann Neurol 6:371-388

Pierce PA, Peroutka SJ (1989): Hallucinogenic drug interactions with neurotransmitter receptor binding sites in human cortex. Psychopharmacology (Berlin) 97:118122

Posner MI, Petersen SE (1990): The attention system of the human brain. Ann Rev Neurosci 13:25-42

Pribram KH (1991): Brain and Perception. Hillsdale, New Jersey, Lawrence Erlbaum Associates

Rhodes CG, Wise RJ, Gibbs JM, Frackowiak RS, Hatazawa J, Palmer AJ, Thomas DG, Jones T (1983): In vivo disturbance of the oxidative metabolism of glucose in human cerebral gliomas. Ann Neurol 14:614-626

Robbins TW (1990): The case for frontostriatal dysfunction in schizophrenia. Schizophren Bull 16:391-402

Rümmele W, Gnirss F (1961): Untersuchungen mit Psilocybin, einer psychotropen Substanz aus Psilocybe Mexicana. Schweizer Archiv für Neurologie, Neurochirurgie und Psychiatrie 87:365-385

Sadzot B, Baraban JM, Glennon RA, Lyon RA, Leonhardt S, Jan CR, Titeler M (1989): Hallucinogenic drug interactions at human brain $5-\mathrm{HT}_{2}$ receptors: implications for treating LSD-induced hallucinogenesis. Psychopharmacology (Berlin) 98:495-499

Sanders-Bush E, Burries KD, Knoth K (1988): Lysergic acid diethylamide and 2,5-dimethoxy-4-methylamphetamine are partial agonists at serotonin receptors linked to phosphoinositide hydrolysis. J Pharmacol Exp Ther 246:924-928

Scharfetter C (1981): Ego-pychopathology: the concept and its empirical evaluation. Psychol Med 11:273-280

Scharfetter C (1987): Paranoid-halluzinatorische Zustandsbilder bei drogeninduzierten Psychosen. In Olbrich HM (ed), Halluzination und Wahn. Berlin, Springer-Verlag, pp. $42-51$

Scharfetter C (1995): The Self-experience of Schizophrenics. Empirical Studies of the Ego/Self in Schizophrenia, Borderline Disorders and Depression. Zürich, University of Zürich

Sheppard G, Manchanda C, Gruzelier J, Hirsch SR, Wise R, Frackowiak RJS, Jones T (1983): 150 Positron emission tomography scanning in predominantly never-treated acute schizophrenic patients. Lancet II:1448-1452 
Siegel BVJ, Buchsbaum MS, Bunney WEJ, Gottschalk LA, Haier RJ, Lohr JB, Lottenberg S, Najafi A, Nuechterlein KH, Potkin SG, Wu JC (1993): Cortical-striatal-thalamic circuits and brain glucose metabolic activity in 70 unmedicated male schizophrenic patients. Am J Psychiatry 150:1325-1336

Talairach J, Bancaud J, Geier S, Bordas-Ferrer M, Szikla G, Rusu M (1973): The cingulate gyrus and human behavior. Electroencephalogr Clin Neurophysiol 34:45-52

Talairach J, Tournoux P (1988): Co-planar Stereotaxic Atlas of the Human Brain. Stuttgart, Thieme

Thatcher K, Kappeler T, Wisecup P, Fischer R (1970): Personality trait dependent performance under psilocybin. II. Dis Nerv Syst 31:181-192

Thatcher K, Wiederholt WC, Fischer R (1971): An electroencephalographic analysis of personality-dependent performance under psilocybin. Agents Actions 2:21-26

Tosi O, Rockey MA, Fischer R (1968): Quantitative measurement of time contraction induced by psilocybin. Arzneimittelforschung 18:535-537

Volkow ND, Brodie JD, Wolf AP, Angrist B, Russell J, Cancro $R$ (1986): Brain metabolism in patients with schizophrenia before and after acute neuroleptic administration. Neurosurg Psychiatry 49:1199-1202

Volkow ND, Wolf AP, van Gelder P, Brodie JD, Overall J, Cancro R, and Gomez-Mont F (1987): Phenomenological correlates of metabolic activity in 18 patients with chronic schizophrenia. Am J Psychiatry 144:151-158

Vollenweider FX (1992): Die Anwendung von Psychotomimetika in der Schizophrenieforschung unter besonderer Berücksichtigung der Ketamin/PCP-Modell-Psychose. SUCHT 38:389-409

Vollenweider FX, Leenders KL, Scharfetter C, Antonini A,
Maguire P, Missimer J, Angst J (in press) (1996): Metabolic hyperfrontality and psychopathology in the ketamine model of psychosis using positron emission tomography (PET) and [F-18]-fluorodeoxyglocose (FDG). Eur Neuropsychopharmacol

Weber AC, Scharfetter C (1984): The syndrome concept: history and statistical operationalizations. Psychol Med $14: 315-325$

Widen L, Blomqvist G, Greitz T, Litton JE, Bergstrom M, Ehrin E, Ericson K, Eriksson L, Ingvar DH, Johansson L, Nilsson JL, Stone Elander S, Sedvall G, Wiesel F, Wiik G (1983): PET studies of glucose metabolism in patients with schizophrenia. Am J Neuroradiol 4:550-552

Wiesel FA, Wik G, Sjörgren I, Blomqvist G, Greitz T, StoneElander S (1987): Regional brain glucose metabolism in drug free schizophrenic patients and clinical correlates. Acta Psychiatr Scand 76:628-641

Wilson FAW, Scalaidhe SPO, Goldman-Rakic PS (1993): Dissociation of object and spatial processing domains in primate prefrontal cortex. Science 260:1955-1958

Wolkin A, Jaeger J, Brodie J, Wolf A, Fowler J, Rotrosen J, Gomez-Mont F, Cancro R (1985): Persistance of cerebral metabolic abnormalities in chronic schizophrenia as determined by positron emission tomography. Am J Psychiatr 142:564-571

Wong DF, Lever Hartig PR, Dannals RF, Villemagne V, Hoffman BJ, Wilson A, Ravert HT, Links JM, Scheffel U, Wagner HN (1987): Localization of serotonin 5- $\mathrm{HT}_{2}$ receptors in living human brain by positron emission tomography using N1-([11C]-Methyl)-2-Br-LSD. Synapse 1:393-398

Wooley DW, Shaw W (1954): A biochemical and pharmacological suggestion about certain mental disorders. Proc Natl Acad Sci USA 40:228-231 